\title{
Asymmetric Kumada Couplings of $\alpha$-Bromo Ketones
}

Metal-Catalyzed

Asymmetric

Synthesis and

Stereoselective

Reactions

Key words

Kumada coupling

bis(oxazoline)s

enantioselectivity

$\alpha$-bromo ketones

nickel

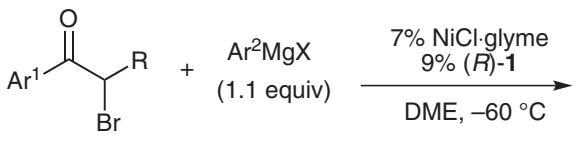<smiles>O=C(Br)C(Br)Br</smiles>

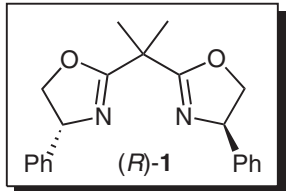

up to $91 \%$ yield up to $95 \%$ ee

$\mathrm{Ar}^{1}=\mathrm{Ph}, 2-\mathrm{FC}_{6} \mathrm{H}_{4}, 3-\mathrm{ClC}_{6} \mathrm{H}_{4}, 4-\mathrm{BrC}_{6} \mathrm{H}_{4}$, 2-thiophenyl, etc.

$\mathrm{Ar}^{2}=\mathrm{Ph}, 2-\mathrm{EtO}_{2} \mathrm{CC}_{6} \mathrm{H}_{4}, 3-\mathrm{BrC}_{6} \mathrm{H}_{4}, 4-\mathrm{F}_{3} \mathrm{CC}_{6} \mathrm{H}_{4}, 4-\mathrm{MeOC}_{6} \mathrm{H}_{4}$, etc.

$\mathrm{R}=\mathrm{Me}, \mathrm{Et}, \mathrm{CH}_{2} \mathrm{CH}_{2} \mathrm{Cl}, \mathrm{CH}_{2} \mathrm{CH}_{2} \mathrm{~N}_{3}, \mathrm{CH}_{2} \mathrm{CH}_{2} \mathrm{OAc}$, etc.

Reactions of dialkyl ketones:

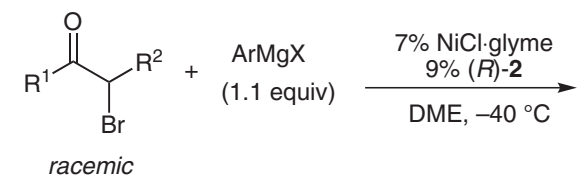

$\mathrm{R}^{1}=\mathrm{CH}_{2} \mathrm{Me}, \mathrm{CH}_{2} \mathrm{Ph}, \mathrm{CH}_{2} \mathrm{Cy}, \mathrm{CHMe}_{2}$

$\mathrm{R}^{2}=\mathrm{Me}, \mathrm{Et}$

$\mathrm{Ar}=\mathrm{Ph}, 4-\mathrm{ClC}_{6} \mathrm{H}_{4}, 4-\mathrm{EtO}_{2} \mathrm{CC}_{6} \mathrm{H}_{4}, 3-\mathrm{BrC}_{6} \mathrm{H}_{4}$, etc

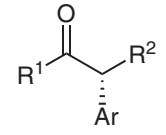

up to $90 \%$ yield up to $73-90 \%$ ee

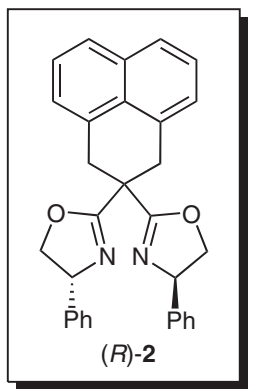

Significance: Kumada reactions (metal-catalyzed couplings of organic electrophiles with Grignard reagents) were among the first studied crosscoupling reactions. Despite the early success of Kumada reactions with alkyl electrophiles, no examples of the enantioselective version have been reported. The authors described a novel asymmetric Kumada coupling of racemic $\alpha$-bromo ketones with aryl Grignard reagents. The scope of the reaction is quite broad, exploiting Knochel's methods for synthesizing functionalized Grignard reagents. High yields and ee values can be obtained, even with dialkyl ketones using modified bis(oxazoline) ligand $\mathbf{2}$. Furthermore, the crosscoupling products can be derivatized with good diastereoselectivity without racemization.
Comment: The reaction is stereoconvergent: both enantiomers of the electrophile are converted into the same enantiomeric product. No evidence for kinetic resolution was observed. The reaction occurs at $-60^{\circ} \mathrm{C}$, the lowest temperature reported for a cross-coupling of an alkyl electrophile. As a consequence, the labile $\alpha$-aryl ketone product is not racemized under the basic conditions. Finally, the readily available bis(oxazolines) have been shown as effective ligands for cross-couplings of alkyl electrophiles for the first time. 